National Aeronautics and

Space Administration

Dryden Flight Research Center

P.O. Box 273

Edwards, California 93523-0273

Reply to

Attn of: Dryden Technical Publications

April 13, 2004

TO: $\quad$ All Holders of NASA/TM-2002-210737, Dated November 2002

FROM: $\quad$ T/Technical Publications Office

SUBJECT: $\quad$ Errata Sheet for NASA/TM-2002-210737, Dated November 2002

NASA/TM-2002-210737, A Ground-Based Research Vehicle for Base Studies at Subsonic Speeds, by Corey Diebler and Mark Smith, has an error in figure 1 on page 3. Please make the following changes to this document.

1. Delete the current text on page 3 .

2. Insert the new attached page 3 with the corrected figure 1 .

3. Staple the errata sheet to the inside front cover of the document.

Thank you for your cooperation.

Michael H. Gorn

Acting Chief of Code T

Attachment

as stated 
Three-dimensional equation: $\quad C_{D_{\text {base }}}=\frac{0.029}{\sqrt{C_{D_{\text {fore }}}}}$

Hoerner's relationship was derived by compiling data from rather small cones, cylinders, fuselage bodies, and projectile shapes. Figure 1 shows Hoerner's two- and three-dimensional base drag relations. When the total aerodynamic drag coefficient, $C_{D_{\text {total }}}$, is plotted against $C_{D_{\text {fore }}}$ (fig. 2), a minimum total drag point where the relationship between forebody and base drag can be optimized clearly can be seen to exist. A vehicle whose $C_{D_{\text {fore }}}$ is less than this optimal point can have its total drag reduced by increasing its forebody drag.

When compared with data from large-scale vehicles, however, Hoerner's base drag relationship appears to underestimate base drag (refs. 2-5), indicating that equation (2) does not provide the most accurate representation of base drag for such vehicles. Reference 3 proposes that this constant could be on the order of 0.09-0.1. Reference 4 states that for many large lifting-body-type vehicles, the local flow at the base region is two-dimensional in nature, indicating that Hoerner's two-dimensional equation should be used.

To better understand the relationship between forebody drag and base drag, a ground research vehicle (GRV) has been constructed. The following sections describe the vehicle, its instrumentation, and the test approach.

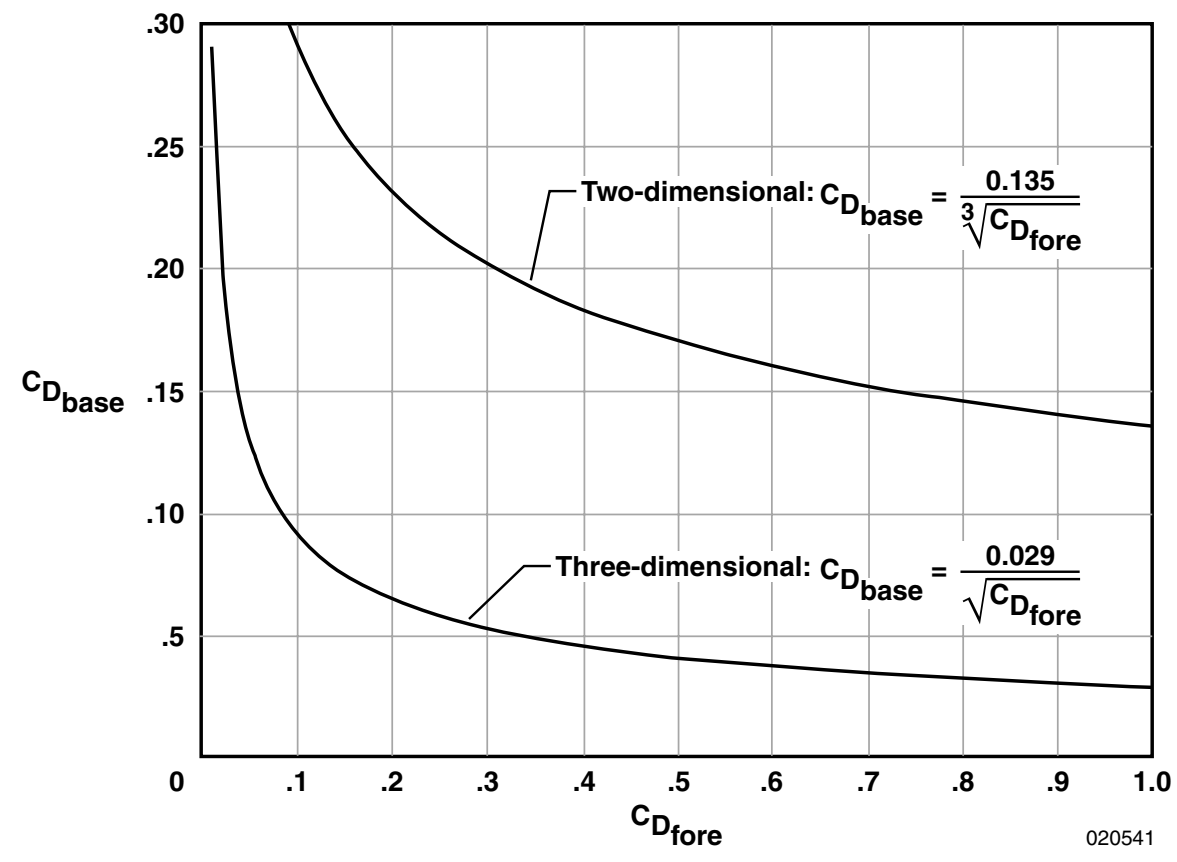

Figure 1. Hoerner's base drag relationship (ref. 1). 
NASA/TM-2002-210737

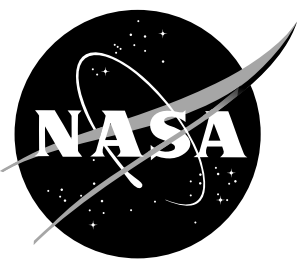

\section{A Ground-Based Research Vehicle for Base Drag Studies at Subsonic Speeds}

Corey Diebler and Mark Smith

NASA Dryden Flight Research Center

Edwards, California 


\section{The NASA STI Program Office...in Profile}

Since its founding, NASA has been dedicated to the advancement of aeronautics and space science. The NASA Scientific and Technical Information (STI) Program Office plays a key part in helping NASA maintain this important role.

The NASA STI Program Office is operated by Langley Research Center, the lead center for NASA's scientific and technical information. The NASA STI Program Office provides access to the NASA STI Database, the largest collection of aeronautical and space science STI in the world. The Program Office is also NASA's institutional mechanism for disseminating the results of its research and development activities. These results are published by NASA in the NASA STI Report Series, which includes the following report types:

- TECHNICAL PUBLICATION. Reports of completed research or a major significant phase of research that present the results of NASA programs and include extensive data or theoretical analysis. Includes compilations of significant scientific and technical data and information deemed to be of continuing reference value. NASA's counterpart of peer-reviewed formal professional papers but has less stringent limitations on manuscript length and extent of graphic presentations.

- TECHNICAL MEMORANDUM. Scientific and technical findings that are preliminary or of specialized interest, e.g., quick release reports, working papers, and bibliographies that contain minimal annotation. Does not contain extensive analysis.

- CONTRACTOR REPORT. Scientific and technical findings by NASA-sponsored contractors and grantees.
- CONFERENCE PUBLICATION.

Collected papers from scientific and technical conferences, symposia, seminars, or other meetings sponsored or cosponsored by NASA.

- SPECIAL PUBLICATION. Scientific, technical, or historical information from NASA programs, projects, and mission, often concerned with subjects having substantial public interest.

- TECHNICAL TRANSLATION. Englishlanguage translations of foreign scientific and technical material pertinent to NASA's mission.

Specialized services that complement the STI Program Office's diverse offerings include creating custom thesauri, building customized databases, organizing and publishing research resultseven providing videos.

For more information about the NASA STI

Program Office, see the following:

- Access the NASA STI Program Home Page at http://www.sti.nasa.gov

- E-mail your question via the Internet to help@sti.nasa.gov

- Fax your question to the NASA Access Help Desk at (301) 621-0134

- Telephone the NASA Access Help Desk at (301) 621-0390

- Write to:

NASA Access Help Desk NASA Center for AeroSpace Information 7121 Standard Drive

Hanover, MD 21076-1320 


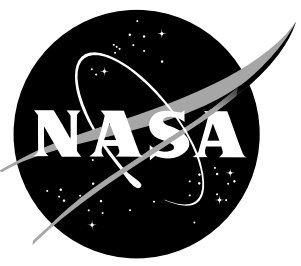

\section{A Ground-Based Research Vehicle for Base Drag Studies at Subsonic Speeds}

Corey Diebler and Mark Smith

NASA Dryden Flight Research Center

Edwards, California

National Aeronautics and

Space Administration

Dryden Flight Research Center

Edwards, California 93523-0273 


\section{NOTICE}

Use of trade names or names of manufacturers in this document does not constitute an official endorsement of such products or manufacturers, either expressed or implied, by the National Aeronautics and Space Administration.

Available from the following:

NASA Center for AeroSpace Information (CASI)

7121 Standard Drive

Hanover, MD 21076-1320

(301) 621-0390
National Technical Information Service (NTIS) 5285 Port Royal Road Springfield, VA 22161-2171

(703) $487-4650$ 


\begin{abstract}
A ground research vehicle (GRV) has been developed to study the base drag on large-scale vehicles at subsonic speeds. Existing models suggest that base drag is dependant upon vehicle forebody drag, and for certain configurations, the total drag of a vehicle can be reduced by increasing its forebody drag. Although these models work well for small projectile shapes, studies have shown that they do not provide accurate predictions when applied to large-scale vehicles. Experiments are underway at the NASA Dryden Flight Research Center to collect data at Reynolds numbers to a maximum of $3 \times 10^{7}$, and to formulate a new model for predicting the base drag of trucks, buses, motor homes, reentry vehicles, and other large-scale vehicles. Preliminary tests have shown errors as great as 70 percent compared to Hoerner's two-dimensional base drag prediction. This report describes the GRV and its capabilities, details the studies currently underway at NASA Dryden, and presents preliminary results of both the effort to formulate a new base drag model and the investigation into a method of reducing total drag by manipulating forebody drag.
\end{abstract}

\title{
NOMENCLATURE
}

$a_{x} \quad$ axial acceleration (positive in the direction the vehicle is moving)

$A_{\text {ref }} \quad$ reference area (vehicle base area)

$C_{D} \quad$ aerodynamic drag coefficient

$C_{D_{\text {base }}} \quad$ base drag coefficient

$C_{D_{\text {fore }}} \quad$ forebody drag coefficient $\left(C_{D_{\text {total }}}-C_{D_{\text {base }}}\right.$ )

$C_{D_{p}} \quad$ drag coefficient caused by pressure forces forward of the base area

$C_{D_{\text {total }}} \quad$ total aerodynamic drag coefficient, $C_{D_{\text {base }}}+C_{D_{\text {fore }}}$

$C_{D_{\text {visc }}} \quad$ drag coefficient caused by viscous losses (includes skin friction and forebody separation vortices)

$C_{p} \quad$ pressure coefficient, $\frac{p-p_{\infty}}{\bar{q}}$

$F_{\text {mech }}$ mechanical drag

GPS global positioning system

GRV ground research vehicle

$m \quad$ vehicle mass

p pressure

$p_{\infty} \quad$ free-stream static pressure

$R \quad$ radius

$V \quad$ true airspeed

$V_{\text {ind }} \quad$ indicated airspeed, $\mathrm{ft} / \mathrm{sec}$

W GRV weight 


$\begin{array}{ll}x, y & \text { cartesian coordinates } \\ \theta & \text { runway slope } \\ \rho & \text { air density }\end{array}$

\section{INTRODUCTION}

Experiments are currently underway at NASA Dryden Flight Research Center (Edwards, California) to investigate a method of reducing vehicle base drag, and thus total aerodynamic drag, by increasing forebody drag. Several types of vehicles are designed with truncated base areas. Trucks, buses, and motor homes are designed such because of their need for large internal volumes. Because of the necessity of the rocket engine at the base, most proposed reusable launch vehicles also have truncated base areas. For all these vehicle types, base drag comprises a major part of the vehicle total drag. The large drag forces that arise decrease the fuel efficiency of ground vehicles or result in steep glide slopes that limit the crossrange and downrange of reentry vehicles. Any reduction in drag is desired because it could greatly increase the overall performance of the vehicle. Drag reductions can reduce the fuel consumption of trucks, buses, and motor homes and lower the required glide slopes for reentry vehicles, making the energy management task considerably easier. Because base drag is such a large element of vehicle total drag, some of the greatest savings could be made in that area.

Hoerner developed an equation (ref. 1) to predict base drag based on the forebody drag coefficient, $C_{D_{\text {fore }}}$, for an object. Such a relationship shows that vehicle base drag can be varied by manipulating forebody drag. Hoerner's equation also suggests that for certain vehicle configurations, the total vehicle drag can be reduced by increasing its forebody drag. This report discusses the ongoing research into Hoerner's equation at Reynolds numbers to a maximum of $3 \times 10^{7}$. Results from initial tests and future plans also are discussed.

\section{BACKGROUND}

Base drag originates at the aft end of an object with a blunt base, or at the trailing edge where the flow separates from the object and a region of low pressure is created. The fast-moving air going past the base acts as a jet pump, pulling air away from the base region, resulting in pressure over the base surface of the object to be reduced (ref. 1).

The boundary layer originating along the surface of a vehicle, or along any object with a blunt trailing edge, has been demonstrated to act as an insulator from the jet pump effect (ref. 1). This insulating effect reduces the effective dynamic pressure of the outer flow, thereby weakening the jet pump effect and resulting in reduced base drag. The thicker the boundary layer, the greater the insulating effect. Because the boundary-layer thickness is dependant on the flow upstream of the base, Hoerner quantifies this effect on two- and three-dimensional objects by relating base drag to forebody drag (ref. 1):

Two-dimensional equation: $\quad C_{D_{\text {base }}}=\frac{0.135}{\sqrt[3]{C_{D_{\text {fore }}}}}$ 
Three-dimensional equation: $\quad C_{D_{\text {base }}}=\frac{0.029}{\sqrt{C_{D_{\text {fore }}}}}$

Hoerner's relationship was derived by compiling data from rather small cones, cylinders, fuselage bodies, and projectile shapes. Figure 1 shows Hoerner's two- and three-dimensional base drag relations. When the total aerodynamic drag coefficient, $C_{D_{\text {total }}}$, is plotted against $C_{D_{\text {fore }}}$ (fig. 2), a minimum total drag point where the relationship between forebody and base drag can be optimized clearly can be seen to exist. A vehicle whose $C_{D_{\text {fore }}}$ is less than this optimal point can have its total drag reduced by increasing its forebody drag.

When compared with data from large-scale vehicles, however, Hoerner's base drag relationship appears to underestimate base drag (refs. 2-5), indicating that equation (2) does not provide the most accurate representation of base drag for such vehicles. Reference 3 proposes that this constant could be on the order of 0.09-0.1. Reference 4 states that for many large lifting-body-type vehicles, the local flow at the base region is two-dimensional in nature, indicating that Hoerner's two-dimensional equation should be used.

To better understand the relationship between forebody drag and base drag, a ground research vehicle (GRV) has been constructed. The following sections describe the vehicle, its instrumentation, and the test approach.

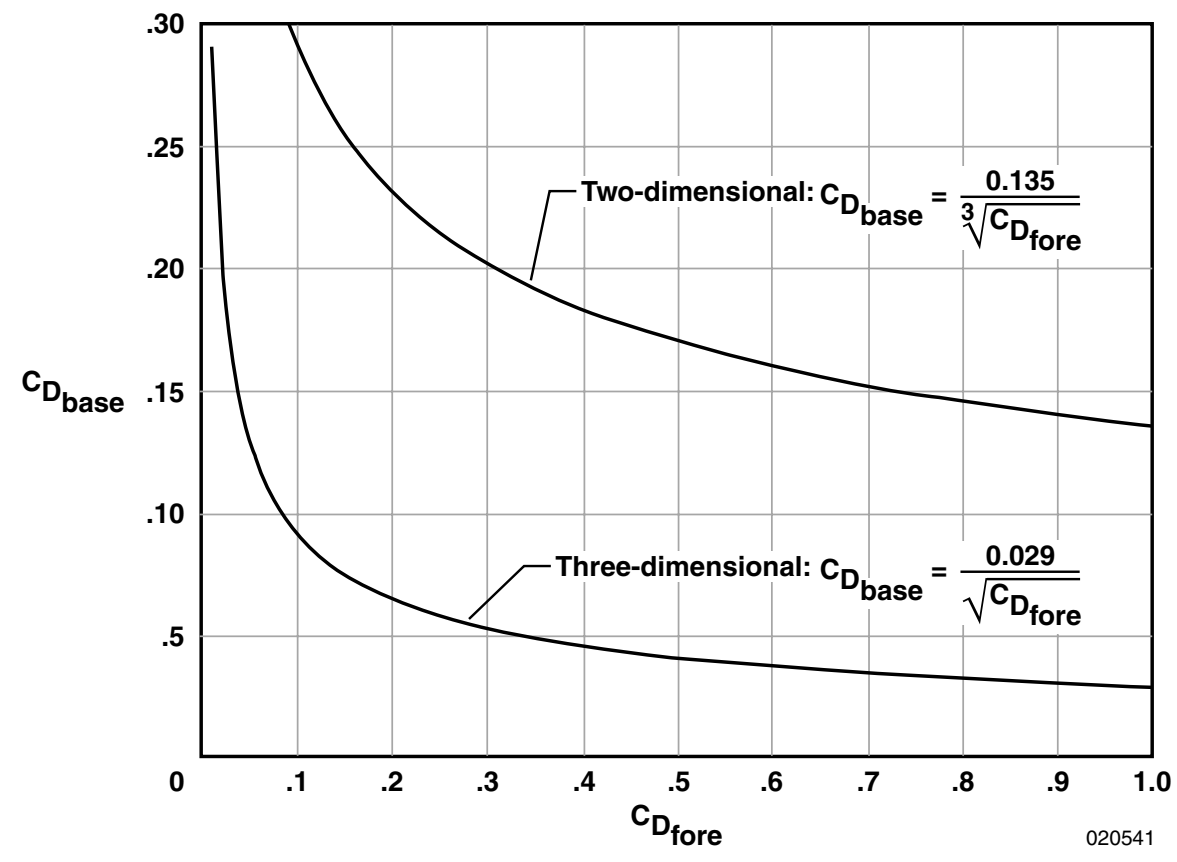

Figure 1. Hoerner's base drag relationship (ref. 1). 


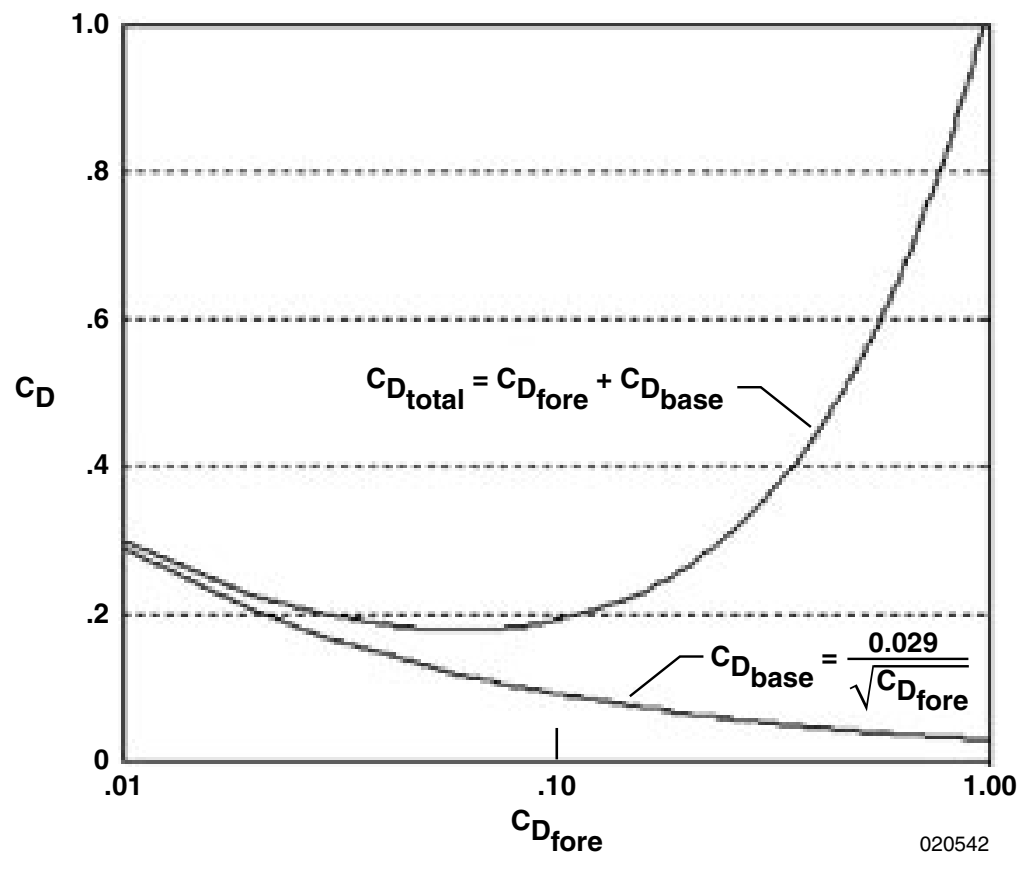

Figure 2. Base and total drag compared with forebody drag (theory).

\section{VEHICLE DESCRIPTION}

The GRV has been designed as a facility to study the relationship between forebody and base drag. The vehicle has been built to a scale that can approximately duplicate the Reynolds numbers experienced by reentry vehicle along their glidepath and by trucks, buses, and motor homes. The GRV is 40-ft long, 9-ft tall, 83-in. wide, and weighs 10,440 $\mathrm{lb}$. The aft end of the underbody has been tapered upwards, giving the GRV a square base area of $83 \times 83 \mathrm{in}^{2}\left(47.84 \mathrm{ft}^{2}\right)$. The base-to-wetted area ratio is approximately 3.8 percent.

The GRV has square leading-edge corners and longitudinal edges along the top, giving the vehicle a box-like geometry. The GRV is capable of speeds exceeding $80 \mathrm{mi} / \mathrm{h}$, providing Reynolds numbers in excess of $3 \times 10^{7}$. Tire pressure is kept nearly constant by inflating the tires with nitrogen to reduce temperature effects. The vehicle also has been modified with a driveline disengage to separate the rear axle from the rest of the drive train for coast-down testing to reduce the mechanical drag caused by turning the engine and transmission.

Two GRV configurations have been tested. Configuration 1 (fig. 3) has an exposed underbody. Airflow under the vehicle circulates among the axles, transmission, mufflers, and exhaust pipes to create additional drag like that on trucks, buses, and motor homes. Configuration 2 has the same outer mold line with the exception of an enclosed underbody, which allows for smoother airflow beneath the vehicle and eliminates any additional pressure drag from the underbody. 


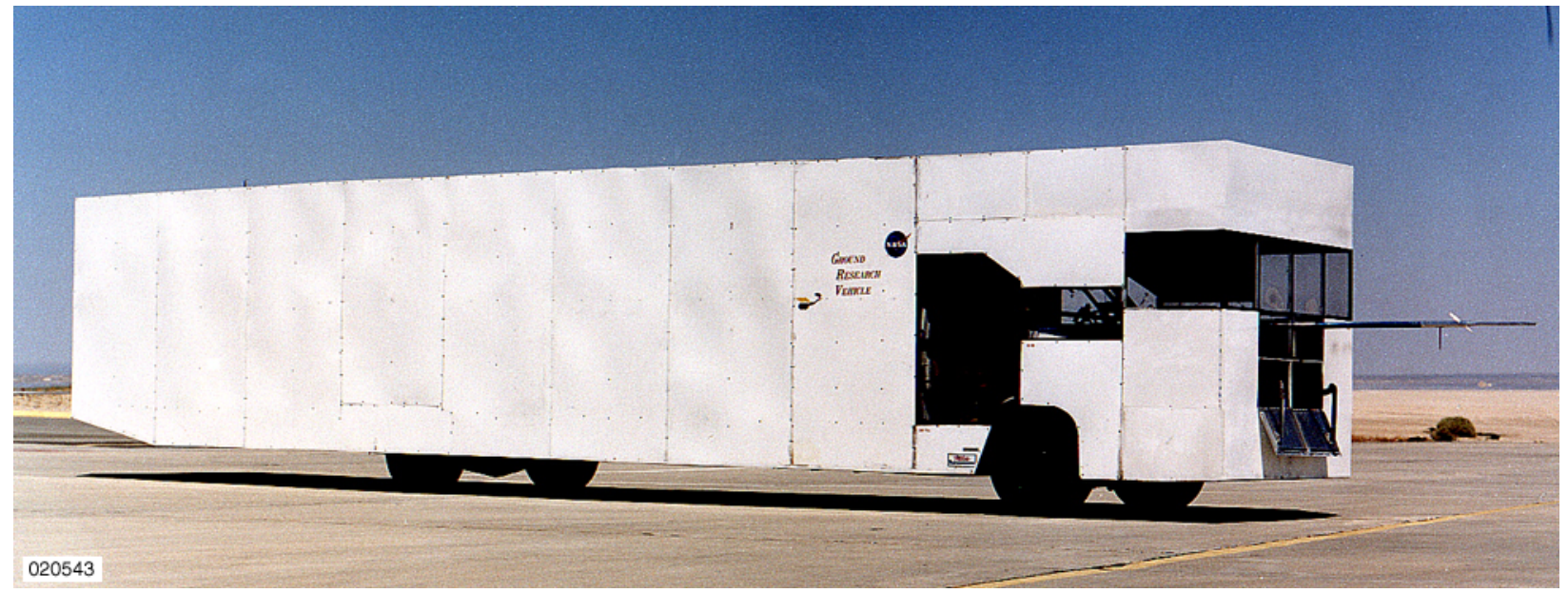

Figure 3. GRV configuration 1.

\section{Instrumentation}

To measure the pressures acting on all of the vehicle surfaces, 125 pressure ports have been installed on the GRV. Two boundary-layer rakes have been mounted on the top aft end of the vehicle to collect boundary-layer information. The smaller of the two rakes (fig. 4) has a dense grouping of pressure probes near the GRV surface to provide an excellent profile of the lower boundary layer (ref. 6). The larger of the two rakes (fig. 5) extends 12 in. from the surface to capture the outer portion of the boundary layer. The GRV has been outfitted with a noseboom to provide free-stream static and total pressure.

Four pressure modules have been installed inside the vehicle, each with 16 individual differential pressure transducers, allowing 64 differential pressures to be simultaneously measured. The pressure transducers are capable of providing differential pressure measurements accurate to within $\pm 0.004 \mathrm{lbf} / \mathrm{in}^{2}$. An absolute pressure transducer has also been installed to measure the differential reference pressure to within $\pm 0.015 \mathrm{lbf} / \mathrm{in}^{2}$.

All pressures are recorded onto a laptop computer. A differential global positioning system (GPS) receiver internally records data during testing. The data are later downloaded to obtain groundspeed (accurate to within $0.5 \mathrm{ft} / \mathrm{sec}$ ), altitude (accurate to within 6 in.), and time. A handheld GPS unit serves as the speedometer and is used as a time stamp to synchronize the differential GPS data with the pressure data. 

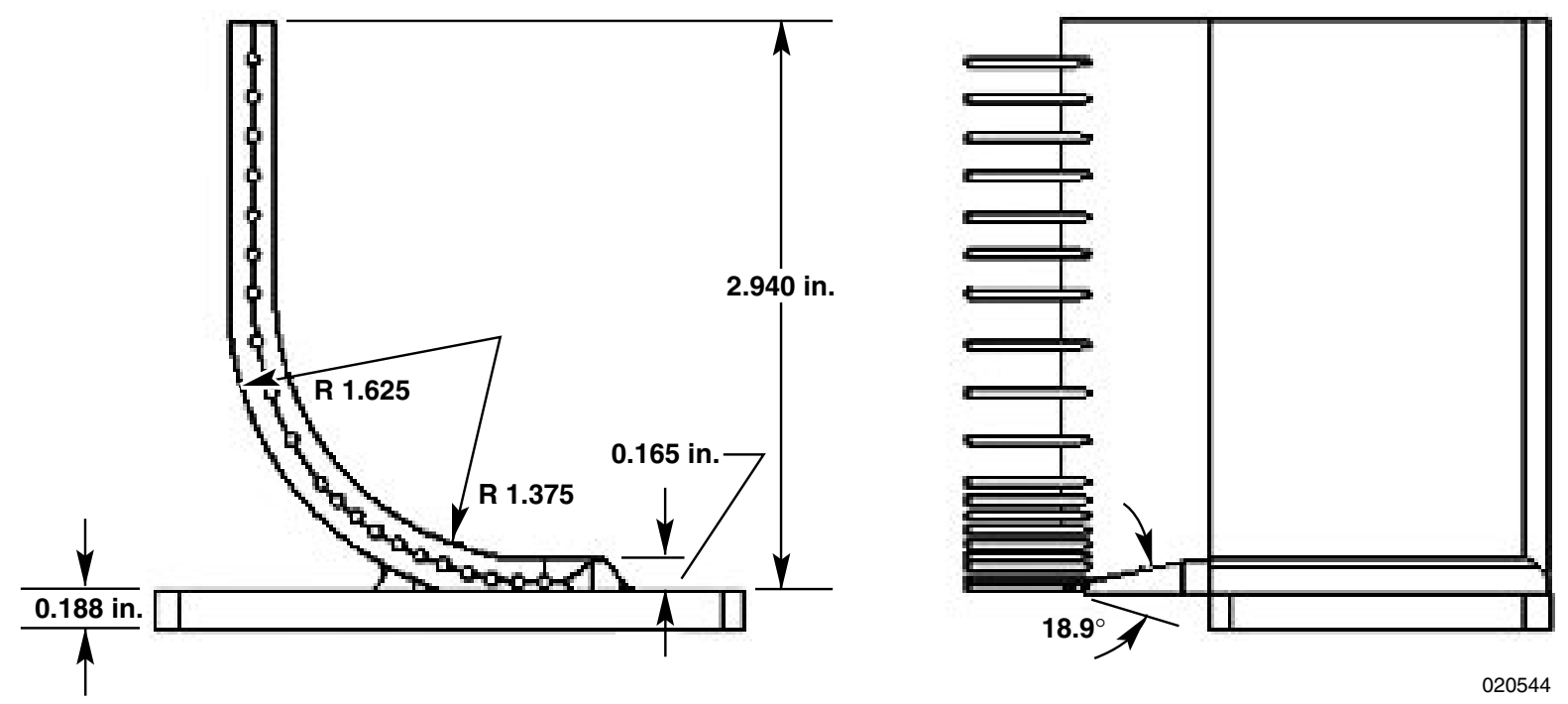

Figure 4. The small boundary-layer rake.

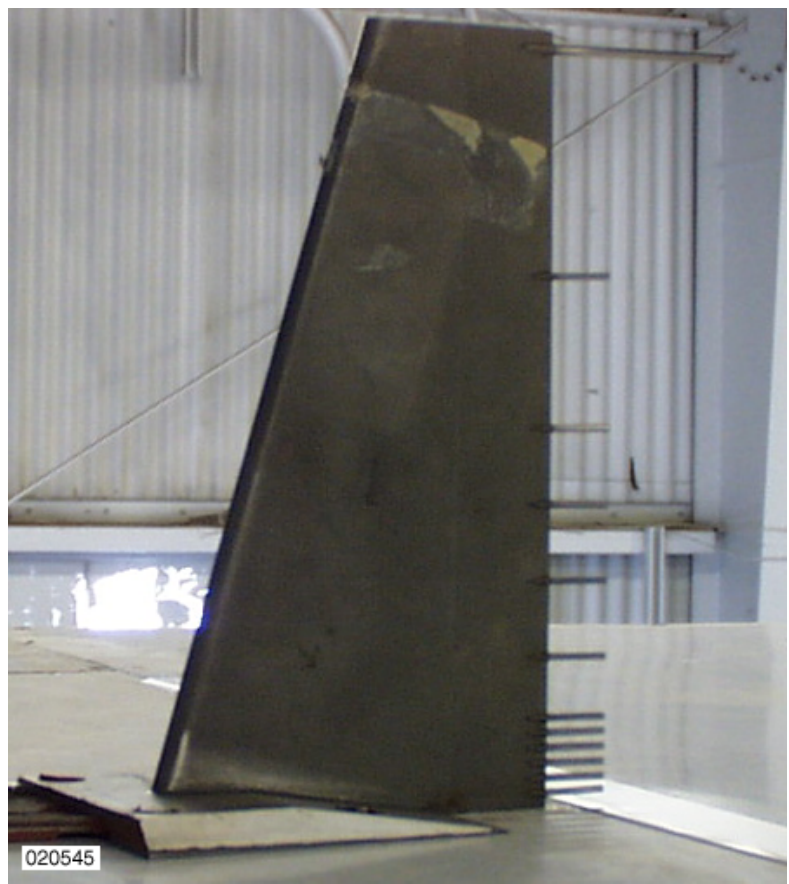

Figure 5. The 12-in. boundary-layer rake mounted on the GRV. 


\section{TEST APPROACH}

The vehicle $C_{D_{\text {total }}}$ is composed of several drag coefficients, including base drag, $C_{D_{\text {base }}}$, and those caused by viscous losses, $C_{D_{\text {visc }}}$, and pressure forces forward of the base area, $C_{D_{p}}$. The $C_{D_{p}}$ includes the pressure forces acting on the front face of the GRV as well as pressure drag originating from wheel wells and the exposed underbody. The $C_{D_{v i s c}}$ includes skin friction as well as drag caused by forebody separation. The $C_{D_{\text {base }}}$ is defined as drag resulting from the low-pressure region at the base of the vehicle.

Two types of tests were devised to obtain the drag components for the GRV. A coast-down method was used to obtain the $C_{D_{\text {total }}}$, and constant speed tests were conducted to break the $C_{D_{\text {total }}}$ into its constituent parts. A portable weather tower measured ambient temperature and windspeed. Testing was not conducted in winds greater than $5 \mathrm{kn}$.

Indicated airspeed was obtained from noseboom total and static pressure measurements. Noseboom static pressure measurements were corrected for position errors using a calibration curve that was generated using the GPS altitude and ambient pressure data. The position error calibration (fig. 6) corrects the measured static pressure as a function of indicated airspeed. True airspeed then was calculated using calibrated static pressure, total pressure, and ambient temperature. All tests were conducted on the north base runway, which is approximately 1-mi long, at Edwards Air Force Base (California).

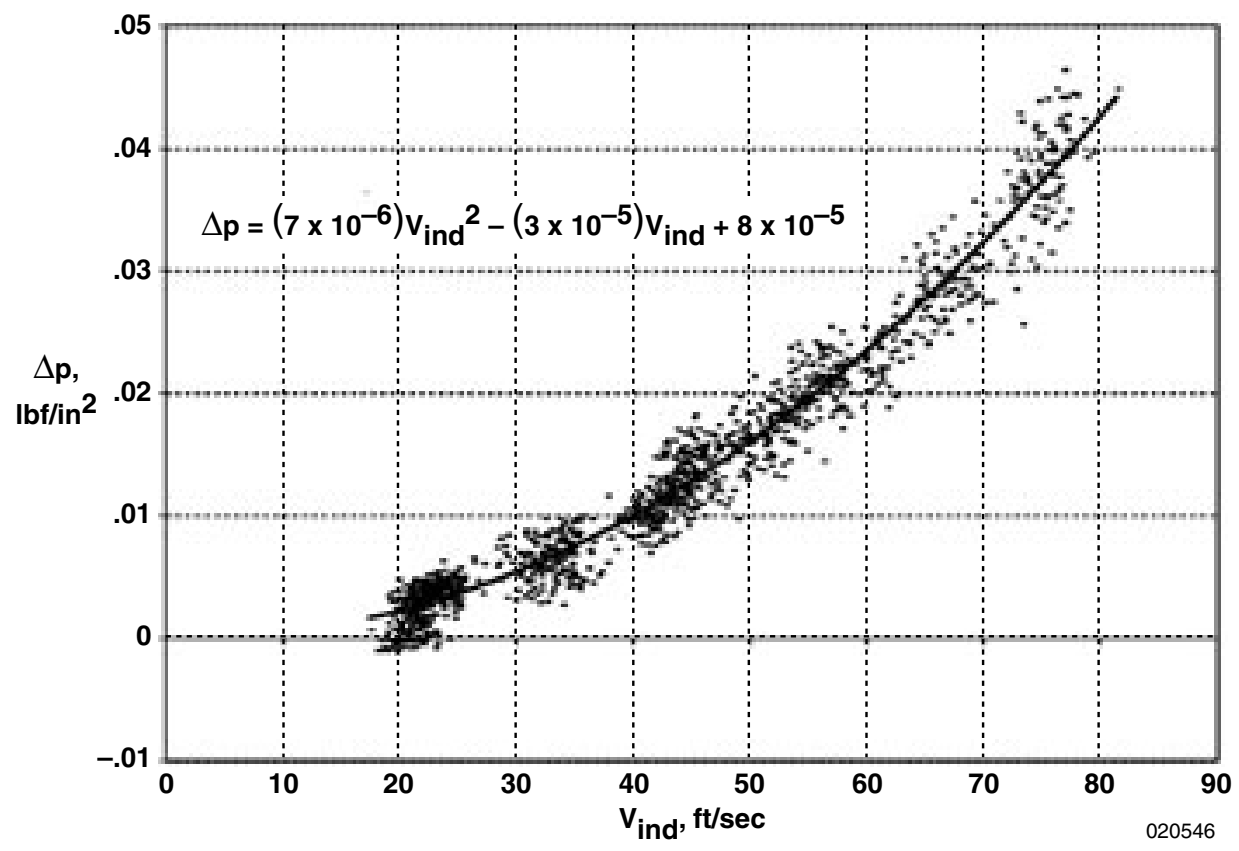

Figure 6. GRV noseboom position error calibration. 


\section{Coast-Down Tests}

In one dimension, the equation of motion for the GRV during a coast-down test is as follows:

$$
m a_{x}=-\frac{1}{2} \rho V^{2} C_{D_{\text {total }}} A_{\text {ref }}-F_{m e c h}-W \sin \theta
$$

where $m$ is vehicle mass, $a_{x}$ is axial acceleration, $A_{r e f}$ is the vehicle base area used as the reference area for these tests, $W$ is the GRV weight, $\rho$ is air density, $V$ is the true airspeed, and $\theta$ is the runway slope. The runway slope was reconstructed using altitude data from the differential GPS unit so $\theta$ could be computed at each point along the runway. Mechanical drag, $F_{\text {mech }}$, encompasses all of the nonaerodynamic losses of the vehicle, including rolling friction, wheel inertia, and mechanical losses. Mechanical losses were significantly reduced by disengaging the drive train before the coasting portion of the test, allowing the wheels to rotate freely without any drag caused by turning the engine or transmission.

Using equation (3), the $C_{D_{\text {total }}}$ of the GRV can be estimated by measuring its deceleration while it coasts. Coast-down tests were performed by accelerating the GRV to a target speed, such as $65 \mathrm{mi} / \mathrm{h}$; disengaging the drive train; and allowing the vehicle to coast to a stop. This technique is commonly used to obtain the aerodynamic drag of vehicles (refs. 7-9). Tests were conducted in both directions along the runway. Ten or more coast-down tests were performed for each configuration.

\section{Constant Speed Tests}

Constant speed tests were conducted at speeds ranging from 20 to $70 \mathrm{mi} / \mathrm{h}$ to obtain data to divide the $C_{D_{\text {total }}}$ into $C_{D_{p}}, C_{D_{\text {visc }}}$, and $C_{D_{\text {base }}}$. To provide the pressure profile acting on the face of the vehicle, 23 surface pressures were measured on the front surface of the GRV. Thirty-two pressures were measured on the base. Figure 7 shows pressure port locations. Using pressures recorded at these locations, least-squares regressions were performed to create polynomial surface fits to the data. Figure 8 shows a typical pressure fit over the front surface. The polynomial surfaces then were integrated over the front and base areas to obtain $C_{D_{p}}$ and $C_{D_{\text {base }}}$.

The box-like shape of the two configurations causes a massive flow separation on the front of the GRV. Evidence of this flow separation can be seen in the flow visualization test (fig. 9) and in pressure data collected along the top surface (fig. 10). Because of this flow separation, full boundary-layer analyses were not performed. The $C_{D_{v i s c}}$ for these configurations was calculated by subtracting the $C_{D_{p}}$ and the $C_{D_{\text {base }}}$ from the estimated $C_{D_{\text {total }}}$ from the coast-down tests:

$$
C_{D_{\text {visc }}}=C_{D_{\text {total }}}-\left(C_{D_{p}}+C_{D_{\text {base }}}\right)
$$




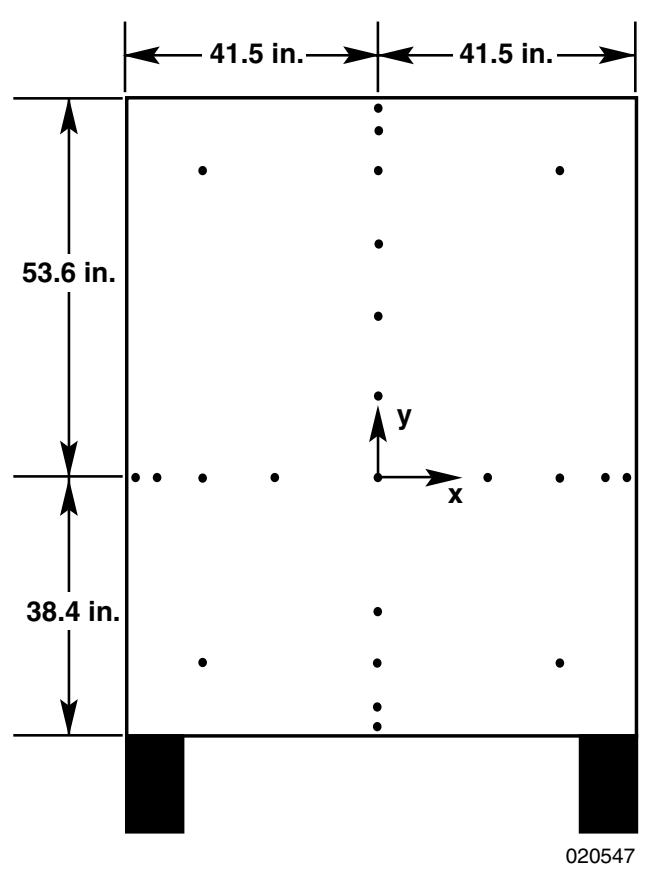

(a) Front locations.

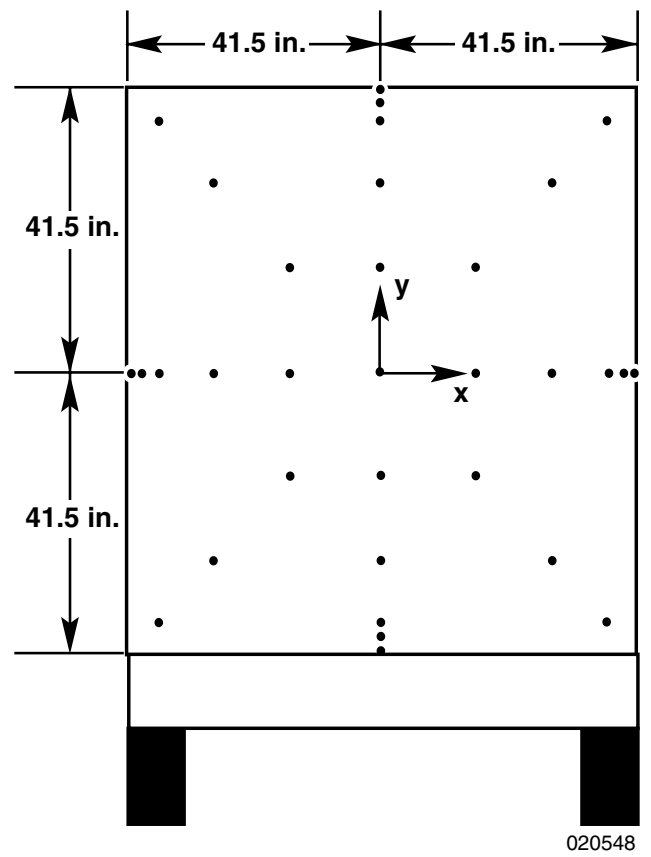

(b) Base locations.

Figure 7. Pressure port locations.

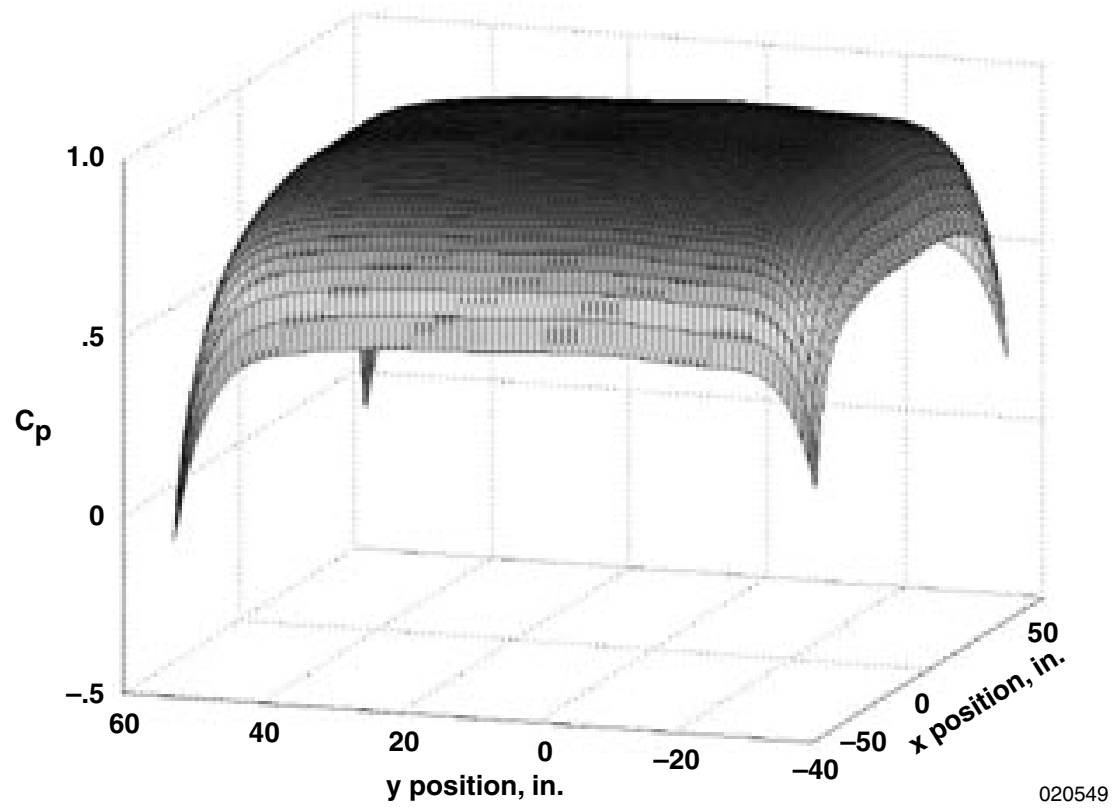

Figure 8. Surface fit to front pressures. 


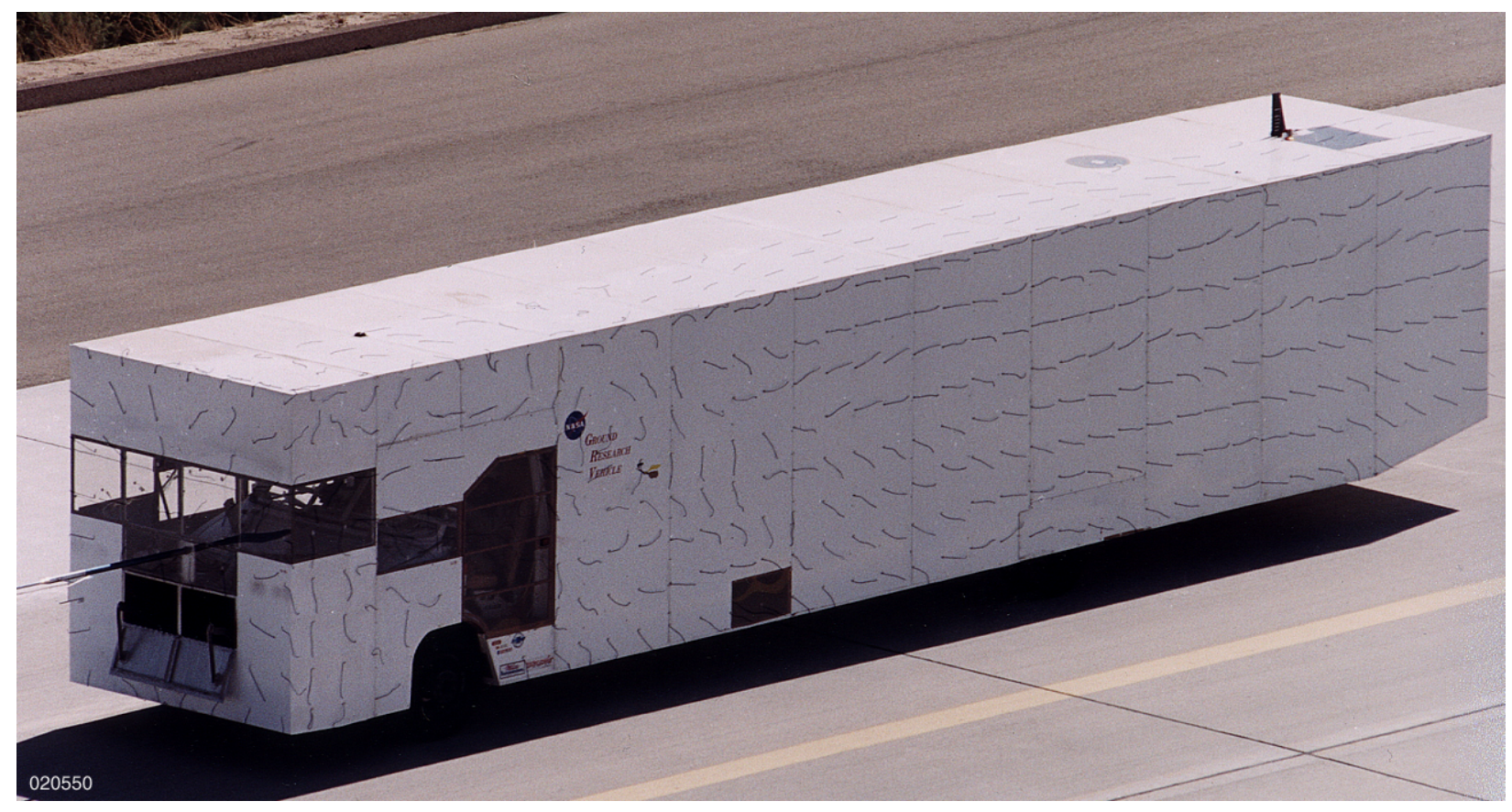

Figure 9. Flow visualization test of GRV configuration 2.

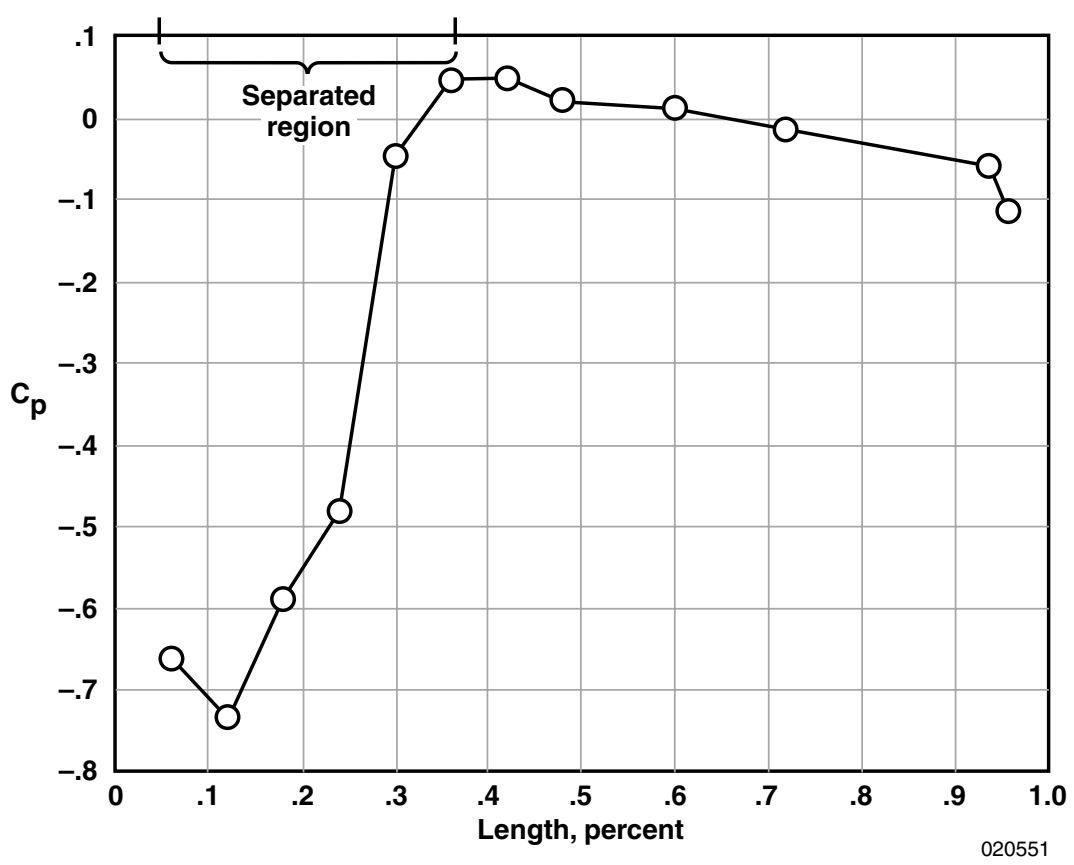

Figure 10. Centerline pressure profile along top of GRV showing flow separation over approximately forward 30 percent of vehicle. 


\section{RESULTS AND DISCUSSION}

Figure 11 shows the results from these two configurations plotted with Hoerner's two-dimensional base drag curves. Table 1 shows averaged results. Figure 11 shows that the GRV total drag data agree well with the predicted value given by Hoerner's two-dimensional equation. Total drag values show a maximum 4-percent error when compared with the predicted value. Base drag values, however, show errors of as much as 70 percent when compared with Hoerner's two-dimensional base drag model. When the numerator in equation (2) is changed to 0.1 as suggested in reference 3 , errors of 120 percent are reached. When compared with Hoerner's three-dimensional model, the errors are greater than 600 percent.

Table 1. Averaged drag results for the GRV.

\begin{tabular}{lccccc}
\hline \hline & $C_{D_{\text {total }}}$ & $C_{D_{p}}$ & $C_{D_{\text {visc }}}$ & $C_{D_{\text {fore }}}$ & $C_{D_{\text {base }}}$ \\
\cline { 2 - 6 } Configuration 1 & 1.26 & 0.75 & 0.32 & 1.08 & 0.18 \\
Configuration 2 & 1.16 & 0.75 & 0.25 & 1.00 & 0.16 \\
\hline \hline
\end{tabular}

The chaotic forebody flow of the current configurations is believed to cause the large errors encountered in predicting the $C_{D_{\text {base }}}$. A future GRV configuration will have rounded leading-edge corners to keep the flow attached over the length of the vehicle. Tests using the future configuration will provide additional data to determine if Hoerner's two-dimensional base drag equation provides the most accurate model for predicting base drag on large-scale vehicles, or if a new model is needed.

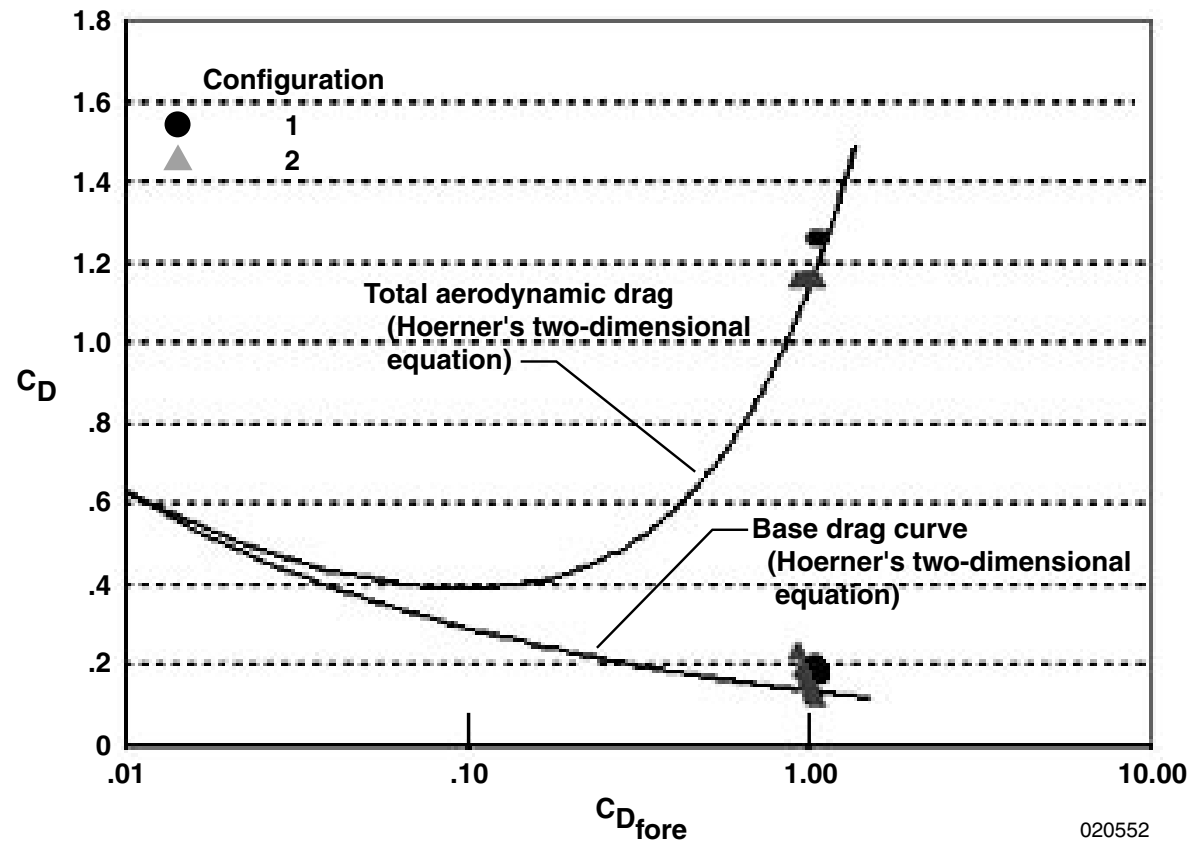

Figure 11. GRV drag study results. 


\section{CONCLUDING REMARKS}

Preliminary tests conducted at NASA Dryden Flight Research Center on two configurations of a ground research vehicle (GRV) provide support for the hypothesis that a new base drag prediction model is needed for large-scale vehicles. Plans currently are underway to begin testing on a third GRV configuration that will include rounded leading-edge corners. This new configuration will allow the boundary layer to remain attached over the entire length of the vehicle and is expected to provide data near the minimum total aerodynamic drag point. Subsequent GRV configurations will increase the surface roughness by adding various-sized boundary-layer trip strips to control the boundary-layer thickness. These future configurations will provide additional data and further studies of effects of forebody drag on base drag. Such test results will either confirm or refute the need for a modified version of Hoerner's base drag equations that applies to large-scale vehicles. Upcoming tests will also provide insight into the feasibility of reducing drag by manipulating the boundary layer.

\section{REFERENCES}

1. Hoerner, Sighard F., Fluid-Dynamic Drag: Practical Information on Aerodynamic Drag and Hydrodynamic Resistance, Self-published work, Library of Congress Card Number 64-19666, Washington, D. C., 1965.

2. Saltzman, Edwin J., K. Charles Wang, and Kenneth W. Iliff, "Flight-Determined Subsonic Lift and Drag Characteristics of Seven Lifting-Body and Wing-Body Reentry Vehicle Configurations With Truncated Bases," AIAA 99-0383, Jan. 1999. (Also published as NASA TP-1999-206573.)

3. Saltzman, Edwin J. and Robert R. Meyer, Jr., A Reassessment of Heavy-Duty Truck Aerodynamic Design Features and Priorities, NASA TP-1999-206574, 1999.

4. Whitmore, Stephen A. and Timothy R. Moes, A Base Drag Reduction Experiment on the X-33 Linear Aerospike SR-71 Experiment (LASRE) Flight Program, NASA TM-1999-206575, 1999.

5. Whitmore, Stephen A., Marco Hurtado, Jose Rivera, and Jonathan W. Naughton, A Real-Time Method for Estimating Viscous Forebody Drag Coefficients, NASA TM-2000-209015, 2000.

6. Bui, Trong T., David L. Oates, and Jose C. Gonsalez, Design and Evaluation of a New Boundary-Layer Rake for Flight Testing, NASA TM-2000-209014, 2000.

7. Lynn, D. K., et al., "Determination of Vehicle Rolling Resistance and Aerodynamic Drag," Los Alamos Scientific Laboratory, LA-UR-78-3229, Mar. 1979.

8. Montoya, Lawrence C. and Louis L. Steers, Aerodynamic Drag Reduction Tests On A Full-Scale Tractor-Trailer Combination With Several Add-On Devices, NASA TM X-56028, 1974.

9. Saltzman, Edwin J., Robert R. Meyer, Jr., and David P. Lux, Drag Reductions Obtained By Modifying a Box-Shaped Ground Vehicle, NASA TM X-56027, 1974. 


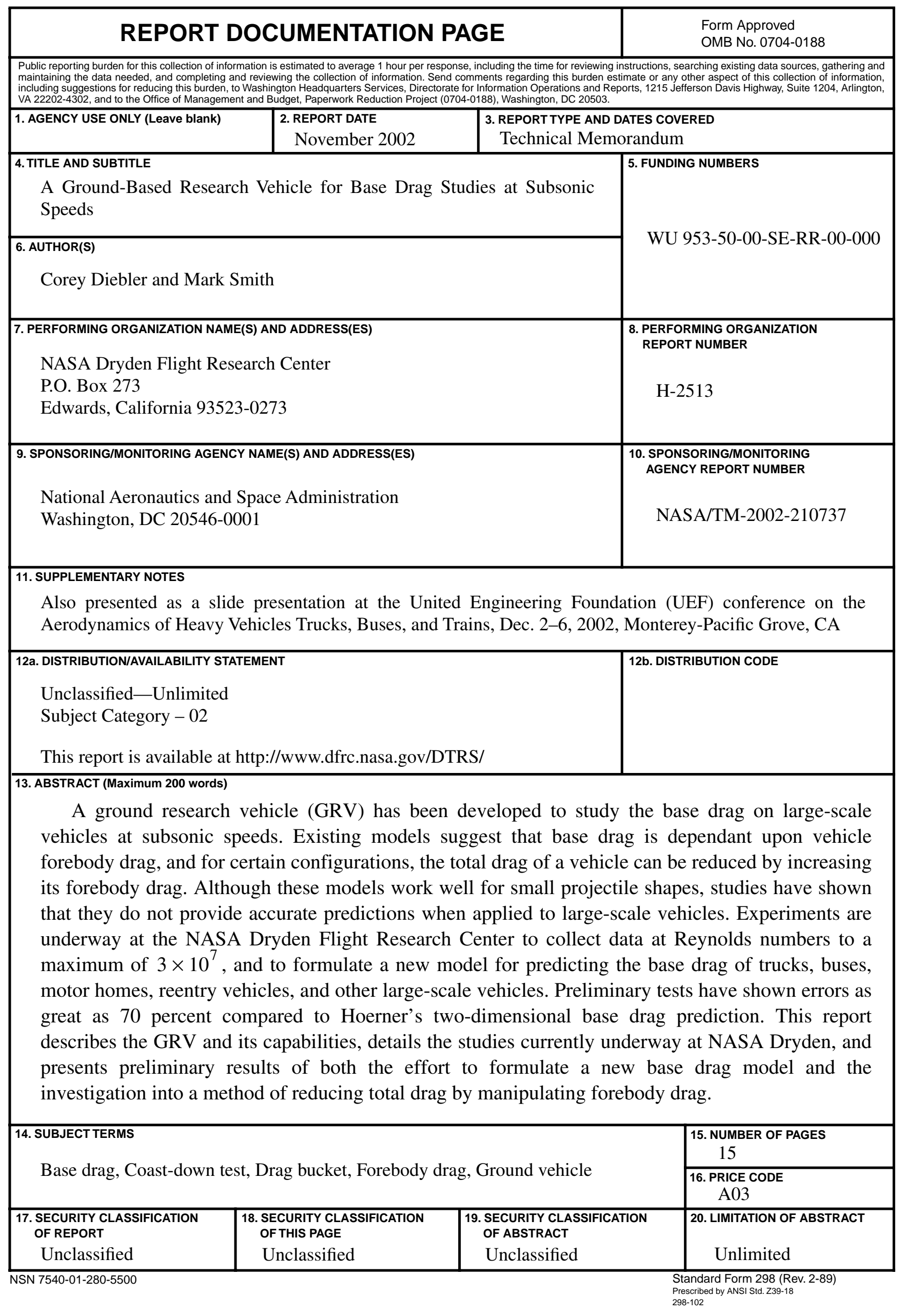

